\title{
Constraining Uncertainties in CMIP5 Projections of Arctic Sea Ice Volume with Observations
}

\author{
Wang Yangjun, Liu Kefeng, Shang Yulong, Zhang Ren \\ College of Meteorology and Oceanography, National University of Defense Technology, Nanjing, 211101, China.
}

Correspondence: Liu Kefeng (1kfnudt@sina.com)

\begin{abstract}
This study proposes adaptive forecasting through exponential re-weighting based on the Structural Similarity Index Measure (AFTER-SSIM) algorithm to evaluate the performance of global climate models from the Coupled Model Intercomparison Project (CMIP5) under different emission scenarios during 2006 to 2018, attempting to reduce the uncertainty among them. The SSIM approach uses a loss function to obtain more information on the spatial distribution between model outputs and observed data, where the genetic algorithm (GA) is used to optimise the parameters of both seasonal cycles and long-term trends of sea ice concentration and sea ice thickness. The re-weighting mechanism of the AFTER-SSIM algorithm guarantees a performance improvement in sea ice volume simulations as new information is added. Finally, the ranked models have been combined to estimate the future Arctic sea ice volume and navigation possibility through the Arctic Northern Sea Route. Results show that the proposed algorithm reduces the uncertainty among models, sea ice volume will continue to shrink in the future, and the open periods for 1A super vessels are likely to reach to five months ranging from August to December in 2030.
\end{abstract}

\section{Introduction}

In a warming climate, the sea ice extent of the Arctic region has shown a consistent decrease, ranging between 3.5\% and $4.1 \%$ every decade from 1979 to 2012 (Stocker et al. 2013). This has contributed to the extended open duration of the Arctic routes and drawn international attention to energy exploration, shipping industry, and its regional ecosystem. The focus of research has shifted from sea-ice loss trends to the open period of the Arctic water (Wang \& Overland, 2015).

Global climate models (GCMs) provided from the Coupled Model Intercomparison Project (CMIP5, Taylor et al.

2012) are currently prevalent in the projection of future sea-ice conditions as the most advanced climate models available for the scientific cycles, showing a continued shrinking and thinning in the sea ice in all future scenarios (Massonnet et al. 2012).

However, large uncertainty exists in the current GCMs for future sea ice projections, caused by the discrepancies in initial conditions or physical processes in the ocean or atmospheric simulation as well as the differences in grid 
https://doi.org/10.5194/os-2020-35

Preprint. Discussion started: 13 May 2020

(c) Author(s) 2020. CC BY 4.0 License.

2018), which block the accurate estimate for the open duration of Arctic routes. Despite these uncertainties, GCMs are powerful tools to understand the future changes in Arctic sea ice. Wang \& Overland, (2009) pointed out that these models could be applied in projections with careful evaluation. Wang \& Overland, (2015) have reduced 37 GCMs to 12 models by taking both the mean trends and seasonal cycles of the September sea ice extent (SSIE) projections from 1981 to 2005 into consideration.

Since 2006, four future scenarios called the Representative Concentration Pathways (RCPs) have been used in all GCMs and defined by their total radiative forcing (a cumulative measure of human emissions of greenhouse gas), i.e. RCP26, RCP45, RCP60, and RCP85 (van Vuuren et al. 2011). The number of realisations of these 12 GCMs extends to 101, leading to new uncertainty. Therefore, this study tries to further access the model performance of 101 candidate realisations from 2006 to 2018 and find a reasonable way to reduce the uncertainty existing in the selected models under different emission scenarios.

Generally, there are two ways to improve the precision of projections; one is to find the model that best fits reality, while the other is to combine estimates with multi-models. In the 1970s, these combined methods were doubted by some researchers due to their lack of theoretical justification (Newbold and Granger 1974). Another argument is that a single best model can be found based on all the information provided by these individual forecasters instead of combining them. However, views have changed over the past 20 years and optimal estimates often face the danger of overfitting (e.g. regression) and lead to high instability. Thus, building such a model is not usually feasible (Yang 2001). Combining estimates is a constructive way that helps to reduce the variability (Chen and Yang 2007). Additionally, few studies have focused on the spatial distribution performance of models, which has been widely evaluated in other meteorological elements (Basharin et al. 2016; Shi et al. 2017). Additionally, the error method (e.g. relative error, root mean square error), widely used in previous literature (Wang and Overland 2015a, 2009, 2012; Massonnet et al. 2011; Stroeve et al. 2012; Liu et al. 2013), cannot suitably fit the difference in spatial distribution (Zhou et al. 2004). Therefore, a combined method called the adaptive forecasting through exponential re-weighting (AFTER) algorithm is incorporated in this study to evaluate the performance of GCMs 
https://doi.org/10.5194/os-2020-35

Preprint. Discussion started: 13 May 2020

(c) Author(s) 2020. CC BY 4.0 License.

The rest of this manuscript is organised as follows: Section 2 introduces the data used in this study and their

features compared with the previous study. The AFTER-SSIM approach, the model ranking workflow, and future sea ice projections are introduced in Section 3. Section 4 shows the results of the model evaluation and combined estimates of future sea ice volume; consequently, the open period of the Arctic water can also be obtained.

\section{Data description}

\subsection{PIOMAS data}

65 Spatial consistency, temporal length, and completeness are key factors in data evaluation (Melia et al. 2015). Therefore, Pan-Arctic Ice-Ocean Modelling and Assimilation System (PIOMAS) sea-ice reanalysis data are used to estimate the observed sea ice condition in this study (Zhang and Rothrock 2003). Despite the uncertainty in the PIOMAS data, the current observation values (i.e. ICEsat or CryoSat-2) have limited spatial coverage and temporal scale, which restrict the model evaluation ability. Large uncertainty and bias still exist in the inversion methods of satellites for driving factors (i.e. sea ice concentration (SIC), sea ice age, and snow depth). The sea ice thickness of the PIOMAS data was observed to fit well with the observations (ICESat field) with less than a 0.1 mean difference and high pattern correlation $(r>0.8)$. The spatial patterns, seasonal cycles, and trends in sea ice thickness (SIT) are realistically reproduced due to atmospheric reanalysis forcings (Labe et al. 2018). Therefore, PIOMAS data have been widely used to represent observations in several studies (Shu et al. 2015; Labe et al. 2018). For temporal consistency, SIC and SIT data were provided by PIOMAS in this study.

\subsection{Multi-model data}

Twelve GCMs, identified by Wang \& Overland, (2015), are used for further evaluation: ACCESS1.0, ACCESS1.3, CCSM4, CESM1(CAM5.1), EC-EARTH, HadGEM2-AO, HadGEM2-CC, HadGEM2-ES, MIROC-ESM, MIROC-ESM-CHEM, MPI-ESM-LR, and MPI-ESM-MR. There are 101 ensemble candidates from these 12

80 models in all emission scenarios. SIC and SIT data are derived from the 12 CMIP5 models to compare with the PIOMAS data. Table 1 presents the basic characteristics of the selected GCMs, where each model has different spatial resolution and ensemble members. 
https://doi.org/10.5194/os-2020-35

Preprint. Discussion started: 13 May 2020

(c) Author(s) 2020. CC BY 4.0 License.

\subsection{Data processing}

Data from GCMs and PIOMAS with different resolutions are interpolated into the same $1^{\circ} \times 1^{\circ}$ resolution. The

monthly data, $X$ are divided into two parts: the seasonal cycle, $\bar{X}$ and the long-term trend with anomalies, $\hat{X}$ as follows:

$X=\bar{X}+\hat{X}$,

\subsection{Spatial variation of sea ice}

The spatial variation of sea ice between the current mean state (2006-2018) and historical mean state (1979-2005)

in March and September, respectively, derived from the PIOMAS data can be seen in Figure 1. Both in March and September, the coverage of sea ice has shrunk compared to the historical period; the decrease in September is more evident than that in March. In March, the reduction of the mean SIC mainly occurs in the Sea of Okhotsk, Barents Sea, and part of the Greenland Sea; in September, the reduction area contains the Beaufort Sea, Chukchi Sea, East Siberian Sea, and Laptev Sea, which extends to $80^{\circ} \mathrm{N}$.

The current mean SIT has thinned down compared to the historical mean SIT. Most of the Arctic area shows a larger reduction of SIT in September than in March. The SIT throughout the Arctic area is no more than 2 meters. For these two months, the variation of mean SIT is more informative than that of mean SIC, especially in the central area, where sea ice thinning can occur without major variations in the local SIC (Melia et al. 2015).

Considering the changes in the spatial distribution for both the mean SIC and mean SIT, the sea ice conditions have varied much. The Northern Sea Routes along the coast of the Chukchi Sea, East Siberian Sea, Laptev Sea, Kara Sea, and Barents Sea begin to be ice-free in September during the current period, as well as the Northwest Passages along the coast of the Beaufort Sea. Therefore, it is necessary to further evaluate model performance in the new period.

\subsection{Temporal variation of sea ice}

Sea ice volume (SIV), which takes both SIC and SIT into consideration, is a good index for the evaluation of model performance (Shu et al. 2015). SIV can be calculated as the sum of the grid cell area of, that is, the SIC and SIT of each grid cell, which can be represented as follows:

$$
S I V=\sum_{\text {lon }=-180}^{180} \sum_{\text {lat }=66.5}^{90} \operatorname{SIT}(\text { lon, lat }) \cdot \operatorname{SIC}(\text { lon, lat }) \cdot 2 \pi r^{2} \cdot\left(\sin \left(\frac{\text { lat }+1}{180} \cdot \pi\right)-\sin \left(\frac{\text { lat }}{180} \cdot \pi\right) / 360\right),
$$


where $r$ is radius of the earth; lon and lat represent the longitude and latitude of the gird, respectively.

Note that although the SIV values from the PIOMAS data are model simulations with data assimilation, they can competently assess the GCMs' performances. The change in monthly average SIV between the historical period and current period can be seen in Figure 2. Compared to the historical period, the SIV has suffered shrunk every month during the current period. In spring, the SIV reaches its peak in April at $29.5 \times 10^{3} \mathrm{~km}^{3}$ in the historical mean (1979-2005) and at $23.4 \times 10^{3} \mathrm{~km}^{3}$ in the current mean (2006-2018). The smallest SIV appears in

115 September at $13.3 \times 10^{3} \mathrm{~km}^{3}$ in the historical mean and at $5.8 \times 10^{3} \mathrm{~km}^{3}$ in the current mean. Additionally, SIV reaches its minimum in September 2012 at $3.79 \times 10^{3} \mathrm{~km}^{3}$, which might have been caused by an unusually strong storm in the central Arctic basin from April to August 2012 (Parkinson and Comiso 2013).

Compared to the period of 1979-2005, the estimated negative trend in SIV is approximately $-35.4 \%$ from 20062018. Additionally, during most of the 2006-2018 period, SIV shows a downward trend with three rebounds in 2008, from 2013-2014, and in 2018. Swart et al. (2015) posited that sea ice change is driven by external forcing and internal variability. SIV rebounds when the effect of the internal variability masks the external forcing. Overall, SIV shows much new information in the period 2006-2018 and is worth studying further.

\section{Methods}

\subsection{Structural Similarity Index Measure (SSIM)}

125 Wang et al. (2004) proposed an objective method for accessing the structural similarity between two images. This method has been widely used in measuring the image quality. Compared to the traditional error methods, this new method termed as the Structural Similarity Index Measure (SSIM) and can better depict the difference in the spatial distribution between two data sets. The formula of the SSIM can be presented as follows:

$$
\operatorname{SSIM}\left(X_{\text {mod }}, X_{\text {obs }}\right)=l\left(X_{\text {mod }}, X_{o b s}\right)^{\alpha} \cdot c\left(X_{\text {mod }}, X_{o b s}\right)^{\beta} \cdot s\left(X_{\text {mod }}, X_{o b s}\right)^{\gamma},
$$

where $l\left(X_{\text {mod }}, X_{o b s}\right)$ represents the variation of mean value, $c\left(X_{\text {mod }}, X_{o b s}\right)$ is the variation of deviation, and $\mathrm{s}\left(X_{\text {mod }}, X_{o b s}\right)$ stands for the structure variation, which can be presented as follows:

$$
\begin{gathered}
l\left(X_{\text {mod }}, X_{o b s}\right)=\frac{\left(2 \mu_{x_{\text {mod }}} \mu_{x_{o b s}}+C_{1}\right)}{\left(\mu_{x_{\text {mod }}}^{2}+\mu_{x_{o b s}}^{2}+C_{1}\right)}, \\
c\left(X_{\text {mod }}, X_{o b s}\right)=\frac{2 \sigma_{x_{\text {mod }}} \sigma_{x_{o b s}}+C_{2}}{\sigma_{x_{\text {mod }}}^{2}+\sigma_{x_{o b s}}^{2}+C_{2}},
\end{gathered}
$$



unstability. If we suppose $\alpha=\beta=\gamma=1, C_{3}=C_{2} / 2$, then the Eq. (3) can be rewritten as follows:

$\operatorname{SSIM}\left(X_{\text {mod }}, X_{o b s}\right)=\frac{\left(2 \mu_{x_{m o d}} \mu_{x_{o b s}}+C_{1}\right)\left(2 \sigma_{x_{m o d} x_{o b s}}+C_{2}\right)}{\left(\mu_{x_{m o d}}^{2}+\mu_{x_{o b s}}^{2}+C_{1}\right)\left(\sigma_{x_{m o d}}^{2}+\sigma_{x_{o b s}}^{2}+C_{2}\right)}$

Let us assume a random matrix $A$ of $10 \times 10$, ranging from 0 to 1 , If 10 is added to the last element, we can obtain matrix $B$. If we add 1 or -1 randomly to each element, matrix $C$ can be obtained. We compare matrix $B$ and $C$ with the original matrix $A$ respectively; the root mean square error (RMSE) of these two are the same, while the SSIM of matrix B and A is larger than that of matrix $\mathrm{C}$ and $\mathrm{A}$, showing that matrix $B$ is structurally more similar to matrix A than matrix $C$ (see Figure 3). This example presents the advantage of SSIM over the RMSE for spatial distribution analysis.

Using this method, we evaluate the structural similarity of the seasonal cycles and the long-term trends in SIC between the GCMs and PIOMAS data, as well as that in SIT. The four scores can be written as follows:

$S C_{j}^{s i c}=\frac{1}{M} \sum_{k=1}^{M} \operatorname{SSIM}\left(\bar{X}_{\text {mod }_{j m}}^{\text {sic }}, \bar{X}_{\text {pio }_{m}}^{\text {sic }}\right)$,

$S C_{j}^{s i t}=\frac{1}{M} \sum_{k=1}^{M} \operatorname{SSIM}\left(\bar{X}_{\text {mod }_{j m}}^{\text {sit }}, \bar{X}_{\text {pio }_{m}}^{s i t}\right)$,

$S T_{j}^{s i c}=\frac{1}{M} \sum_{k=1}^{M} \operatorname{SSIM}\left(\hat{X}_{\text {mod }_{j m}}^{\text {sic }}, \hat{X}_{\text {pio }_{m}}^{\text {sic }}\right)$,

$S T_{j}^{s i t}=\frac{1}{M} \sum_{k=1}^{M} \operatorname{SSIM}\left(\hat{X}_{\text {mod }_{j m}}^{\text {it }}, \hat{X}_{\text {pio }_{m}}^{\text {sit }}\right)$,

150 where $S C_{j}^{s i c}$ and $S C_{j}^{\text {sit }}$ are the similarities in the seasonal cycles of SIC (CSIC) and SIT (CSIT) between the $j$ th ensemble member of GCMs and PIOMAS data, respectively; $S T_{j}^{s i c}$ and $S T_{j}^{s i t}$ are the similarities in the longterm trends of SIC (TSIC) and SIT (TSIT) between the $j$ th ensemble member of GCMs and PIOMAS data, respectively; and $M$ is the number of the time series. 


\subsection{AFTER-SSIM method}

155 Yan (2001) first proposed the scheme of the AFTER algorithm to develop combinations for better forecasts. Simulations and real data examples have shown the advantages and applications of the AFTER algorithm (Altavilla and Grauwe 2010; Rapach and Strauss 2008; Sánchez 2008; Shu et al. 2009), which is defined as:

$$
W_{i, j}=\frac{\prod_{k=1}^{i-1} \hat{s}_{k, j}^{-1 / 2} \exp \left(-\lambda L\left(\frac{Y_{k}-\hat{y}_{k, j}}{\hat{s}_{k, j}}\right)\right)}{\sum_{j^{\prime}=1}^{J} \prod_{k=1}^{i-1} \hat{s}_{k, j}^{-1 / 2} \exp \left(-\lambda L\left(\frac{Y_{k}-\hat{y}_{k, j}}{\hat{s}_{k, j}}\right)\right)},
$$

where $W_{i, j}$ is the weight of each model $j \in \Theta$ at each time $i \in \mathrm{I}$; note that $\sum_{j=1}^{\infty} W_{i, j}=1$ for $i \geq 1, \lambda$ is a tuning parameter to control the degree of weighting dependence on the predictive performance (Wei and Yang 2011).

The L1 loss function used in this manuscript can be written as follows:

$L\left(\frac{Y_{k}-\hat{y}_{k, j}}{\hat{s}_{k, j}}\right)=\left|\frac{Y_{k}-\hat{y}_{k, j}}{\hat{s}_{k, j}}\right|$,

The variance $\hat{s}_{k, j}$ can be estimated as follows:

$\hat{s}_{k, j}=\frac{1}{i-1} \sum_{k=1}^{i-1}\left|Y_{k}-\hat{y}_{k, j}\right|$

Generally, relative error is used in majority of the studies to distribute the weights of candidate models (e.g. Wei and Yang 2012; Yang 2001), where $Y_{k}$ represents the PIOMAS data at time $K$, while $\hat{y}_{k, j}$ represents the $j$ th model data at time $K$. In this study, instead of relative error, a new form has been established to represent the difference between the model outputs and PIOMAS data, which can be presented as follows:

$Y_{k}-\hat{y}_{k, j}=\exp \left(-2 \cdot\left(\alpha_{1} S C_{j}^{s i c}+\alpha_{2} S C_{j}^{s i t}+\alpha_{3} S T_{j}^{s i c}+\alpha_{4} S C_{j}^{s i c}\right)\right)$,

where $S C_{j}^{s i c}, S C_{j}^{s i t}, S T_{j}^{s i c}, S C_{j}^{s i c}, j \in \Theta$ are derived from SSIM, $\alpha$ is the weight vector, and $\sum_{m=1}^{4} \alpha_{m}=1$. Note that, the weight factor in this study has been optimised by the genetic algorithm (GA) (Whitley 1994).

The ensemble forecast procedure $\hat{y}_{i}^{*}$ can be represented as:

$\hat{y}_{i}^{*}=\sum_{j \in \Theta} W_{i, j} \hat{y}_{i, j}$

where $i$ is the projection time. 
$W_{i, j}=\frac{W_{i-1, j} \exp \left(-\lambda L\left(\frac{Y_{k^{-}}-\hat{y}_{k, j}}{\hat{s}_{k, j}}\right)\right)}{\sum_{j^{\prime}} W_{i-1, j^{\prime}} \exp \left(-\lambda L\left(\frac{Y_{k}-\hat{y}_{k, j}}{\hat{s}_{k, j}}\right)\right)}$,

After each additional observation, the weights of each model can be updated. Thus, we call this algorithm adaptive forecasting through an exponential re-weighting method. Specifically, the common AFTER algorithm is termed as AFTER-RE and the new form AFTER algorithm is termed as AFTER-SSIM.

\subsection{Navigability of the Arctic routes}

The navigability of the Arctic Routes can be represented by the Ice Numeral (IN) index derived from the Arctic Ice Regime Shipping System (AIRSS), where both SIC and SIT are taken into consideration (Howell and Yackel 2004; Smith and Stephenson 2013; Stephenson and Smith 2015; CanadaTransport 1998). The IN is given by

$I N=C_{a} I M_{a}+C_{b} I M_{b}+\cdots+C_{n} I M_{n}$,

where $C_{n}$ is the concentration in tenths of ice type $n$ and $I M_{n}$ is the Ice Multiplier for ice type $n$. Ice-type describes the specific stage of ice development, which is closely related to the ice age and thickness. Ice Multipliers (a series of integers), determined by ship class and ice type, are used to illustrate the impact of sea ice type on a specific vessel. $I M<0$ reflects the ice obstacle effects on vessels. Ice types are determined by CanadaTransport, (1998) and Johnston, (2017). Note that the area can be navigable only if the IN index is larger than zero. Details regarding the ice type and Ice Multiplier can be seen in Tables 2 and 3.

\subsection{Work flow}

The workflow of the proposed method can be seen in Figure 4. In Step 1, the PIOMAS data and model are interpolated into the same $1^{\circ} \times 1^{\circ}$ resolution, and the original data are separated into the seasonal cycles and longterm trends with anomalies. In Step 2, the seasonal cycle in the model data is compared with that in the PIOMAS data by the SSIM method to reflect the model's reaction to the seasonal variation of the solar cycle. The SSIM method is also used to calculate the long-term trends between multi-models and PIOMAS to reflect the model's fidelity to the real world. In Step 3, we proposed an AFTER-SSIM algorithm to calculate the weights for every model and generate an ensemble forecast for the future sea ice volume (SIV), where the seasonal cycle scores (CSIC/CSIT), as well as the long-term trend scores (TSIC/TSIT), are incorporated into the loss function and variance estimation. The parameters in the AFTER-SSIM algorithm can be optimised by GA. Additionally, the 
https://doi.org/10.5194/os-2020-35

Preprint. Discussion started: 13 May 2020

(c) Author(s) 2020. CC BY 4.0 License.

candidate realisations are ranked in terms of their weights. In Step 4, the calculated weights are used to modify the SIC and SIT fields; then, the future open period of the Arctic sea routes can be obtained.

\section{Results and Discussion}

\subsection{Scores from SSIM between GCMs and PIOMAS data}

A total of 101 candidate members from the 12 models were selected by Wang \& Overland, (2015) in all emission

scenarios. Based on the workflow proposed in Section 3.1, we can obtain four kinds of SSIM scores for each ensemble model (see Figure 5). From Figure 5, all the realisations have better performances in the simulation of seasonal cycles than in long-term trends. The average scores of the seasonal cycles between all GCMs and PIOMAS data can reach 0.7717 for SIC and 0.7427 for SIT. HadGEM2-AO, HadGEM2-CC, and HadGEM2-ES show better performances in the simulation of the seasonal cycles of SIC, while MPI-ESM-LR and MPI-ESMMR show the best performances in the simulation of the seasonal cycles of SIT. MIROC-ESM, MIROC-ESMCHEM, MPI-ESM-LR, and MPI-ESM-MR have advantages in modelling SIT trends, while MPI-ESM-LR and MPI-ESM-MR have advantages in simulating SIC trends.

\subsection{Model rank based on sea ice volume}

To further rank the models in terms of their performance in sea ice conditions, we introduce these four SSIM as an index to measure the model performance of both SIC and SIT. The simulation results can be seen in Table 4 and Figure 6.

Table 4 compares the simulation performance of SIV based on different methods and their stability by computing the RMSE between GCMs and PIOMAS data. The variable $n$ represents the number of months used in the training from 2006-2017; all 12 months in 2018 are used to test the model performance. AFTER-SSIM is the proposed method in this study, AFTER-RE is the AFTER algorithm that uses relative error as the loss function, LR is the linear regression method, GRNN is the generalised regression neural network, RF represents the random forest algorithm, Mean is the average outcome of all the models, and Single is the optimal model among the realisations. From Table 4, RF has the lowest RMSE if the samples are less than 144 but becomes large when the sample number reaches 144 , thus, demonstrating some instability. 
The AFTER-SSIM algorithm has the second-lowest RMSE among all the schemes with robust stability. The GRNN algorithm shows good performances in both RMSE and stability, while the model performance of LR deteriorates rapidly as the number of samples decreases.

The difference between AFTER-SSIM and AFTER-RE is the choice of loss functions. The SSIM approach can determine more information than the RE method, which was discussed in Section 3.1; thus, AFTER-SSIM has a lower RMSE than AFTER-RE. Additionally, the weights of the AFTER-SSIM algorithm can be updated by adding new observations (see Eq. (17)) to steadily improve the accuracy of combined forecasts in SIV, showing advantages over the GRNN and RF algorithms. Overall, AFTER-SSIM is a good tool to obtain combined forecasts. Then, the weights of candidate realisations can be obtained by the AFTER-SSIM algorithm (see Figure 6). The top 34 candidate realisations, only accounting for $33 \%$ of the total members, contribute $90.7 \%$ of the weight in the combined forecast, as listed in Table 5. Considering Figure 6 and Table 5, the candidate realisations from MPIESM-LR have the largest weights $(41.27 \%)$, followed by candidate realisations from MPI-ESM-MR (11.18\%), CCSM4 (24.73\%), MIROC-ESM (6.99\%), and MIROC-ESM-CHEM (6.53\%), which are key factors in the combined projection. Models from ACCESS1.0, ACCESS1.3, CESM4, EC-EARTH, HADGEM2-AO, HADGEM2-CC, and HADGEM2-ES have relative low weights and contribute less to the combined projection.

Then, Shannon's entropy is used as a tool to measure the variation of uncertainty between the initial candidate realisations and ranked models (Shannon, 1948). The formula can be written as follows:

$U_{k}=\sum_{j=1}^{\widetilde{I}}-p_{k} \ln \left(p_{k}\right), \mathrm{k}=1,2$

where $U_{1}$ is the uncertainty of original candidate realisations, $U_{2}$ is the uncertainty of the ranked candidate realisations, and $p_{k}, k=1,2$ represents the possibility of each model. For the original candidate realisations, the possibility $p_{1}$ for each model is equal to $1 / 101$, while for the ranked models the possibility $p_{2}$ for each model is substituted by the weights derived from the AFTER-SSIM algorithm. Hence, the uncertainty is reduced from 4.6152 $(\ln 101)$ to $3.9061(\approx \ln 50)$ by the AFTER-SSIM algorithm, indicating that the information originally scattered in the 101 candidate realisations has been concentrated into approximately 50 models. by the AFTER-SSIM algorithm, based on the optimal loss function (red line), fits the PIOMAS data (black line) well, except for the simulation of some extreme values (e.g. the high values in 2006, 2008-2009 and 2015 and the 
low values in 2010-2013 and 2016-2017). This issue can be explained by the predictability of CMIP5 models and reliability of observations. For CMIP5 models, most large-scale physical sea ice processes, including basic thermodynamic and dynamic changes, have been well understood and represented (Hunke et al. 2011). However, some details in the small-scale sea ice dynamic process and mechanical deformation require closer examination (Girard et al. 2009; Hutchings et al. 2011). Some snow processes such as wind redistribution, vapour transport, and snow particle changes are not contained in the models (Lecomte et al. 2011). Studies show that the internal variability of sea ice has accounted for 30-50\% of the total observed sea ice change since 1979 (Ding et al. 2017). The sensitivity of sea ice to atmospheric circulation changes in CMIP5 models is lower than what has been observed (Rosenblum and Eisenman 2017). For example, research has suggested that the record low SIV in 2012 may have been caused by an unusually strong storm in the central Arctic basin from April to August 2012 (Parkinson and Comiso 2013), which cannot be represented well by CMIP5 models. This has made the reconstructed SIV appear higher than PIOMAS data. Regarding observation precision, studies have shown that the satellite retrieval algorithms of SIV often neglect snow thickness changes (Bunzel et al. 2018), as well as numerous geophysical parameter assumptions (e.g. seawater, snow load, and snow and sea ice densities) (Zygmuntowska et al. 2014). The current main obstacle to improving the projection of SIV is the lack of longterm and reliable SIV estimates (Massonnet et al. 2018).

Regardless of the extreme cases, an obvious decrease trend can be seen in the period of 2019-2030 in terms of our combined forecast. Similar to the 2006-2018 period, the change in SIV in the future will not be a consistent shrinking as it might rebound in 2020-2021, 2023-2024, and 2028-2029.

\subsection{Navigability for future Arctic Northern Sea Route}

For further exploration of the navigability of the Arctic Northern Sea Route, we combined all the candidate realisations with their weights to predict the opening period of the Northern Sea Route in 2030. The SIC and SIT data from 101 candidate realisations are sorted into 11 categories (i.e. $C_{n}, n=\{0,1, \ldots, 10\}$ ) and 9 categories (i.e. ice type), respectively. Then the possibility of navigability on each grid can be calculated as follow:

$P_{i}=\sum_{j=1}^{N}\left(C_{i j} \times I M_{i j} \times W_{j}\right)$, if $\left(C_{i j} \times I M_{j}\right)>0, i \in \Theta$,

where $N$ is the number of candidate realisations and $W_{j}, j=1, \ldots, N$ is the weight of each model. The possibility of navigability for 1A super vessels (the most advanced ice-strengthened vessels) on Northern Sea Route for each 
https://doi.org/10.5194/os-2020-35

Preprint. Discussion started: 13 May 2020

(c) Author(s) 2020. CC BY 4.0 License.

month in 2030 can be seen in Figure 8. It is likely that in the South Barents Sea and Kara Sea, 1A super vessels will be navigable throughout 2030. For the Northern Sea Routes, 1 A super vessels are unlikely (less than $60 \%$ ) to be permitted to sail north of $80^{\circ} \mathrm{N}$ throughout most of 2030. The Laptev Sea, East Siberian Sea, and Chukchi Sea are likely (more than $80 \%$ ) to be interconnected when August comes, lasting until December. Therefore, the possibility of $1 \mathrm{~A}$ super vessels navigating on the Northern Sea Routes for 5 months (from August to December) in 2030 is more than $80 \%$.

\subsection{Summary}

This study proposes a new algorithm called AFTER-SSIM to evaluate the performance of 101 selected global climate models under four different emission scenarios, appearing since 2006.

The SSIM approach is incorporated into the algorithm as a loss function to obtain more information on the spatial distribution between model outputs and PIOMAS data, allowing the AFTER-SSIM algorithm to perform better than the AFTER-RE algorithm. The GA method is used to optimise the parameters in seasonal cycles and longterm trends of SIC and SIT. The re-weighting mechanism of the AFTER-SSIM algorithm ensures the improved performance in SIV simulations as new information is added, showing better performances than other listed regression methods.

The combined forecasts in SIV with 101 global climate models show that there will be an obvious decrease trend with some rebounds from 2019 to 2030. The invalidity of extreme SIV projection reveals that closer examination is needed for both the physical processes and parameterisations in global climate models as well as to obtain more reliable and long-term observations.

The ranked models are combined to calculate the navigation possibility for 1A super vessels through the Northern Sea Route in 2030. A possibility beyond $80 \%$ indicates that the open period can reach five months, ranging from August to December in 2030.

\section{Acknowledgements}

This work is supported by the National Natural Science Foundation of China (41375002). The PIOMAS data set used in this study is provided by the Polar Science Center and can be accessed at http://psc.apl.uw.edu/research/projects/arctic-sea-ice-volume-anomaly/data/. Data from multi global climate 
https://doi.org/10.5194/os-2020-35

Preprint. Discussion started: 13 May 2020

(c) Author(s) 2020. CC BY 4.0 License.

models including ACCESS1.0, ACCESS1.3, CCSM4, EC-EARTH, CESM1(CAM5.1), HadGEM2-AO, HadGEM2-CC, HadGEM2-ES, MIROC-ESM, MIROC-ESM-CHEM, MPI-ESM-LR, and MPI-ESM-MR used in this study are provided by the fifth phase of the Coupled Model Intercomparison Project (CMIP5), which are available at https://esgf-node.llnl.gov/search/cmip5/.

\section{References}

Altavilla, C., and P. De Grauwe, 2010: Forecasting and combining competing models of exchange rate determination. Appl. Econ., 42, 3455-3480.

Basharin, D., A. Polonsky, and G. Stankūnavičius, 2016: Projected precipitation and air temperature over Europe

using a performance-based selection method of CMIP5 GCMs. J. Water Clim. Chang., https://doi.org/10.2166/wcc.2015.081.

Bi, D., and Coauthors, 2013: The ACCESS coupled model: description, control climate and evaluation. Aust. Meteorol. Oceanogr. J., https://doi.org/10.22499/2.6301.004.

Bunzel, F., D. Notz, and L. T. Pedersen, 2018: Retrievals of Arctic Sea-Ice Volume and Its Trend Significantly

320 Affected by Interannual Snow Variability. Geophys. Res. Lett., https://doi.org/10.1029/2018GL078867.

CanadaTransport, 1998: ARCTIC ICE REGIME SHIPPING SYSTEM (AIRSS) STANDARDS -TP 12259.

Chen, Z., and Y. Yang, 2007: Time series models for forecasting: Testing or combining? Stud. Nonlinear Dyn. Econom., 11, https://doi.org/10.2202/1558-3708.1385.

Ding, Q., and Coauthors, 2017: Influence of high-latitude atmospheric circulation changes on summertime Arctic sea ice. Nat. Clim. Chang., 7, 289-295, https://doi.org/10.1038/nclimate3241.

Fichefet, T., and M. A. M. Maqueda, 1999: Modelling the influence of snow accumulation and snow-ice formation on the seasonal cycle of the Antarctic sea-ice cover. Clim. Dyn., 15, 251-268.

Gent, P. R., and G. Danabasoglu, 2011: Response to Increasing Southern Hemisphere Winds in CCSM4. J. Clim., 24, 4992-4998.

Girard, L., J. Weiss, J. M. Molines, B. Barnier, and S. Bouillon, 2009: Evaluation of high-resolution sea ice models on the basis of statistical and scaling properties of Arctic sea ice drift and deformation. J. Geophys. Res., 114, https://doi.org/10.1029/2008jc005182. 
https://doi.org/10.5194/os-2020-35

Preprint. Discussion started: 13 May 2020

(c) Author(s) 2020. CC BY 4.0 License.

Howell, S. E. L., and J. J. Yackel, 2004: A vessel transit assessment of sea ice variability in the Western Arctic, 1969-2002: Implications for ship navigation. Can. J. Remote Sens., 30, 205-215, https://doi.org/10.5589/m03-062.

Hunke, E. C., W. H. Lipscomb, and A. K. Turner, 2011: Sea-ice models for climate study: Retrospective and new directions. J. Glaciol., 56, 1162-1172.

Hutchings, J. K., A. Roberts, C. A. Geiger, and J. Richter-Menge, 2011: Spatial and temporal characterization of sea-ice deformation. Ann. Glaciol., https://doi.org/10.3189/172756411795931769.

Johnston, M. E., 2017: Cold Regions Science and Technology Seasonal changes in the properties of fi rst-year , second-year and multi-year ice. Cold Reg. Sci. Technol., 141, 36-53, https://doi.org/10.1016/j.coldregions.2017.05.006.

Labe, Z., G. Magnusdottir, and H. Stern, 2018: Variability of Arctic sea ice thickness using PIOMAS and the CESM large ensemble. J. Clim., 31, 3233-3247, https://doi.org/10.1175/JCLI-D-17-0436.1.

Lecomte, O., T. Fichefet, M. Vancoppenolle, and M. Nicolaus, 2011: A new snow thermodynamic scheme for large-scale sea-ice models. Ann. Glaciol., 5257, 337-346(10).

Liu, J., S. Mirong, Horton Radley M, and H. Yongyun, 2013: Reducing spread in climate model projections of a September ice-free Arctic. Proc. Natl. Acad. Sci. U. S. A., 110, 12571-12576.

Massonnet, F., T. Fichefet, H. Goosse, M. Vancoppenolle, P. Mathiot, and G. Lema^, 2011: The Cryosphere On the influence of model physics on simulations of Arctic and Antarctic sea ice. 687-699, https://doi.org/10.5194/tc5-687-2011.

Massonnet, F., F. Thierry, G. Hugues, C. M. Bitz, G. Philippon-Berthier, M. M. Holland, and B. P.-Y, 2012: Constraining projections of summer Arctic sea ice. The Cryosphere,6,6(2012-11-22), 6, 1383-1394.

—, M. Vancoppenolle, H. Goosse, D. Docquier, T. Fichefet, and E. Blanchard-Wrigglesworth, 2018: Arctic sea-ice change tied to its mean state through thermodynamic processes. Nat. Clim. Chang., 8, 599-603, https://doi.org/10.1038/s41558-018-0204-z.

Mclaren, A. J., H. T. Banks, C. F. Durman, J. M. Gregory, and S. W. Laxon, 2006: Evaluation of the sea ice simulation in a new coupled atmosphere-ocean climate model (HadGEM1). J. Geophys. Res., 111, C12014.

Melia, N., K. Haines, and E. Hawkins, 2015: Improved Arctic sea ice thickness projections using bias-corrected CMIP5 simulations. 2237-2251, https://doi.org/10.5194/tc-9-2237-2015. 
https://doi.org/10.5194/os-2020-35

Preprint. Discussion started: 13 May 2020

(c) Author(s) 2020. CC BY 4.0 License.

360 Newbold, P., and C. W. J. Granger, 1974: Experience with Forecasting Univariate Time Series and the Combination of Forecasts. J. R. Stat. Soc. Ser. A, 137(2), 131-165., https://doi.org/10.2307/2344546.

Notz, D., F. A. Haumann, H. Haak, J. H. Jungclaus, and J. Marotzke, 2013: Arctic sea-ice evolution as modeled by Max Planck Institute for Meteorology’s Earth system model. J. Adv. Model. Earth Syst., 5, 173-194.

Parkinson, C. L., and J. C. Comiso, 2013: On the 2012 record low Arctic sea ice cover: Combined impact of preconditioning and an August storm. Geophys. Res. Lett., https://doi.org/10.1002/grl.50349.

Rapach, D. E., and J. K. Strauss, 2008: Forecasting US Employment Growth Using Forecast Combining Methods.

J. Forecast., 27, 75-93.

Rosenblum, E., and I. Eisenman, 2017: Sea ice trends in climate models only accurate in runs with biased global warming. J. Clim., https://doi.org/10.1175/JCLI-D-16-0455.1.

Sánchez, I., 2008: Adaptive combination of forecasts with application to wind energy. Int. J. Forecast., 24, 679-

693.

Shannon, C. E., 1948: The mathematical theory of communication. 1963. MD. Comput., 14, 306-317, https://doi.org/10.1002/j.1538-7305.1948.tb01338.x.

Shi, F., Z. Wang, L. Qi, R. Chen, S. Li, and Z. Tian, 2017: A score based method for assessing the performance of GCMs in the Yellow-Huai-Hai region. 6th International Conference on Energy and Environmental Protection, Vol. 143 of, $744-751$

Shu, F., L. Chen, and W. J. Lee, 2009: Short-Term Load Forecasting Using Comprehensive Combination Based on Multimeteorological Information. IEEE Trans. Ind. Appl., 45, 1460-1466.

Shu, Q., Z. Song, and F. Qiao, 2015: Assessment of sea ice simulations in the CMIP5 models. https://doi.org/10.5194/tc-9-399-2015.

Smith, L. C., and S. R. Stephenson, 2013: New Trans-Arctic shipping routes navigable by midcentury. 2013, 610, https://doi.org/10.1073/pnas.1214212110.

Stephenson, S. R., and L. C. Smith, 2015: Influence of climate model variability on projected Arctic shipping futures. Earth’s Futur., 3, 331-343, https://doi.org/10.1002/2015EF000317.

385 Stocker, T. F., and Coauthors, 2013: Climate change 2013 the physical science basis: Working Group I contribution to the fifth assessment report of the intergovernmental panel on climate change. 
https://doi.org/10.5194/os-2020-35

Preprint. Discussion started: 13 May 2020

(c) Author(s) 2020. CC BY 4.0 License.

Stroeve, J. C., V. Kattsov, A. Barrett, M. Serreze, T. Pavlova, M. Holland, and W. N. Meier, 2012: Trends in Arctic sea ice extent from CMIP5, CMIP3 and observations. Geophys. Res. Lett., 39, 16502.

Swart, N. C., J. C. Fyfe, E. Hawkins, J. E. Kay, and A. Jahn, 2015: Influence of internal variability on Arctic seaice trends. Nat. Clim. Chang., 5, 86-89.

Taylor, K. E., R. J. Stouffer, and G. A. Meehl, 2012: An Overview of CMIP5 and the Experiment Design. Bull. Am. Meteorol. Soc., 93, 485-498.

van Vuuren, D. P., and Coauthors, 2011: The representative concentration pathways: An overview. Clim. Change, https://doi.org/10.1007/s10584-011-0148-z.

395 Wang, M., and J. E. Overland, 2009: A sea ice free summer Arctic within 30 years? Geophys. Res. Lett., 36, https://doi.org/10.1029/2009GL037820.

— and - 2012: A sea ice free summer Arctic within 30 years: An update from CMIP5 models. Geophys. Res. Lett., 39, 6-11, https://doi.org/10.1029/2012GL052868.

— and J. E. Overland, 2015a: Projected future duration of the sea-ice-free season in the Alaskan Arctic. Prog.

Oceanogr., 136, 50-59.

— and J. E. Overland, 2015b: Projected future duration of the sea-ice-free season in the Alaskan Arctic. Prog. Oceanogr., 136, 50-59, https://doi.org/10.1016/j.pocean.2015.01.001.

Watanabe, M., M. Chikira, Y. Imada, and M. Kimoto, 2011: Convective control of ENSO simulated in MIROC.

J. Clim., 24, 543-562.

Wei, X., and Y. Yang, 2011: Robust Combination of Model Selection Methods for Projection. Stat. Sin., 22, https://doi.org/10.5705/ss.2010.023.

Whitley, D., 1994: A genetic algorithm tutorial. Stat. Comput., https://doi.org/10.1007/BF00175354.

Wu, L., X. Yang, and J. Hu, 2018: Assessment of Arctic sea ice simulations in CMIP5 models. 1-29.

Yang, Y., 2001: Combining forecasting procedures: Some theoretical results. Econom. Theory, 20, 176-222, https://doi.org/10.1017/S0266466604201086.

Zhang, J., and D. A. Rothrock, 2003: Modeling Global Sea Ice with a Thickness and Enthalpy Distribution Model in Generalized Curvilinear Coordinates. Mon. Weather Rev., https://doi.org/10.1175/15200493(2003)131<0845:mgsiwa>2.0.co;2. 
https://doi.org/10.5194/os-2020-35

Preprint. Discussion started: 13 May 2020

(c) Author(s) 2020. CC BY 4.0 License.

Zhou, W., B. Alan Conrad, S. Hamid Rahim, and Simoncelli Eero P, 2004: Image quality assessment: from error

Zygmuntowska, M., P. Rampal, N. Ivanova, and L. H. Smedsrud, 2014: Uncertainties in Arctic sea ice thickness and volume: New estimates and implications for trends. The Cryosphere,8,2(2014-04-22), 7, 5051-5095.

Table 1: Basic features of the 12 CMIP5 models used for analysis.

\begin{tabular}{|c|c|c|c|c|c|c|c|c|}
\hline \multirow{2}{*}{$\begin{array}{l}\text { Model } \\
\text { Number }\end{array}$} & \multirow[t]{2}{*}{ Model Name } & \multirow[t]{2}{*}{ Country } & \multirow[t]{2}{*}{ Spatial Resolution } & \multicolumn{4}{|c|}{$\begin{array}{c}\text { Ensemble members } \\
\text { (RCP) }\end{array}$} & \multirow[t]{2}{*}{ Reference } \\
\hline & & & & 26 & 45 & 60 & 85 & \\
\hline 1 & ACCESS 1.0 & Australia & $\begin{array}{l}\text { tripolar, } 1^{\circ} \times 1^{\circ} \text {, } \\
\text { refinement at the equator }\end{array}$ & & 1 & & 1 & (Bi et al. 2013) \\
\hline 2 & ACCESS 1.3 & Australia & $\begin{array}{l}\text { tripolar, } 1^{\circ} \times 1^{\circ} \text {, } \\
\text { refinement at the equator }\end{array}$ & & 1 & & 1 & (Bi et al. 2013) \\
\hline 3 & CCSM4 & USD & $\begin{array}{l}\text { dipolar, } 1.11^{\circ} \times(0.27- \\
0.54)^{\circ}, \mathrm{NP} \text { in Greenland }\end{array}$ & 5 & 6 & 6 & 6 & $\begin{array}{c}\text { (Gent and } \\
\text { Danabasoglu 2011) }\end{array}$ \\
\hline 4 & CESM1 & USD & $\begin{array}{c}\text { dipolar, } 1.11^{\circ} \times(0.27- \\
0.54)^{\circ}, \text { NP in Greenland }\end{array}$ & 3 & & & 1 & $\begin{array}{c}\text { (Gent and } \\
\text { Danabasoglu 2011) }\end{array}$ \\
\hline 5 & EC-EARTH & Europe & $\begin{array}{l}\text { tripolar, } 1^{\circ} \times 1^{\circ} \text {, } \\
\text { refinement at the equator }\end{array}$ & 2 & 10 & & 10 & $\begin{array}{c}\text { (Fichefet and } \\
\text { Maqueda 1999) }\end{array}$ \\
\hline 6 & HadGEM2-ES & UK & $(1-0.3)^{\circ} \times 1^{\circ}$ & 4 & 4 & 4 & 5 & $\begin{array}{l}\text { (Mclaren et al. } \\
\text { 2006) }\end{array}$ \\
\hline 7 & HadGEM2-CC & UK & $(1-0.3)^{\circ} \times 1^{\circ}$ & 1 & 1 & 1 & 1 & $\begin{array}{c}\text { (Mclaren et al. } \\
\text { 2006) }\end{array}$ \\
\hline 8 & HadGEM2-AO & Korea & $(1-0.3)^{\circ} \times 1^{\circ}$ & & 1 & & 3 & $\begin{array}{c}\text { (Mclaren et al. } \\
\text { 2006) }\end{array}$ \\
\hline 9 & MIROC-ESM & Japan & $\sim 1.4^{\circ} \times 1^{\circ}$ & 1 & 1 & 1 & 2 & $\begin{array}{l}\text { (Watanabe et al. } \\
\text { 2011) }\end{array}$ \\
\hline 10 & $\begin{array}{l}\text { MIROC-ESM- } \\
\text { CHEM }\end{array}$ & Japan & $\sim 1.4^{\circ} \times 1^{\circ}$ & 1 & 1 & 1 & 1 & $\begin{array}{l}\text { (Watanabe et al. } \\
\text { 2011) }\end{array}$ \\
\hline 11 & MPI-ESM-LR & Germany & $\sim 1.5^{\circ} \times 1.5^{\circ}$ & 3 & 3 & & 3 & (Notz et al. 2013) \\
\hline 12 & MPI-ESM-MR & Germany & $\sim 0.4^{\circ} \times 0.4^{\circ}$ & 1 & 3 & & 1 & (Notz et al. 2013) \\
\hline Sum & & & & 21 & 32 & 13 & 35 & \\
\hline
\end{tabular}


https://doi.org/10.5194/os-2020-35

Preprint. Discussion started: 13 May 2020

Table 2: Ice Type (CanadaTransport, 1998; Johnston, 2017).

\begin{tabular}{|c|c|}
\hline Ice Type & Characteristic \\
\hline Open Water & $\begin{array}{l}\text { Newly formed ice, include ice crystal, grease like ice, crushed ice clusters, etc. These types of ice are } \\
\text { loosely frozen together and can only been seen while floating. The ice thickness is less than } 10 \mathrm{~cm} \text {. }\end{array}$ \\
\hline Grey & $\begin{array}{l}\text { Young ice has a thickness of } 10-15 \mathrm{~cm} \text {, which is lower than that of nilas and is easy to expand and } \\
\text { break. }\end{array}$ \\
\hline Grey-white & Young ice has a thickness of $15-30 \mathrm{~cm}$. \\
\hline $\begin{array}{l}\text { Thin first year } \\
\text { 1st stage }\end{array}$ & One-year ice, of which the formation time does not exceed one winter, has a thickness of $30-50 \mathrm{~cm}$. \\
\hline $\begin{array}{l}\text { Thin first year } \\
\text { 2nd stage }\end{array}$ & One-year ice, of which the formation time does not exceed one winter, has a thickness of $50-70 \mathrm{~cm}$. \\
\hline $\begin{array}{l}\text { Medium first } \\
\text { year }\end{array}$ & One-year ice has a thickness of $70-120 \mathrm{~cm}$. \\
\hline Thick first year & One-year ice has a thickness of $120-220 \mathrm{~cm}$. \\
\hline Second year & Adult ice, which has gone through at least one summer melting, has a thickness of $220-250 \mathrm{~cm}$. \\
\hline Multiyear & Multiyear ice, which has gone through at least two summer meltings, has a thickness beyond $250 \mathrm{~cm}$. \\
\hline
\end{tabular}

Table 3: Ice Multiplier for 1A Super (CanadaTransport 1998).

\begin{tabular}{cccccccccc}
\hline & Open & Grey & Grey & Thin First Year & Thin FIRST & Medium & Thick & Year 2nd \\
& Water & Ice & White & First & First & Second & Multi \\
& & Ise & 1st Stage & Stage & Year & Year & Year & Year \\
\hline 1A Super & 2 & 2 & 2 & 2 & 2 & 1 & -1 & -3 & -4 \\
\hline
\end{tabular}

425 Table 4: Comparison for the simulation performance of SIV based on different methods and their stability (n is the number of months used in the training from 2006-2017; all 12 months in 2018 are used to test the model performance)

\begin{tabular}{cccccc}
\hline Method/Sample & $\mathrm{n}=96$ & $\mathrm{n}=108$ & $\mathrm{n}=120$ & $\mathrm{n}=132$ & $\mathrm{n}=144$ \\
\hline AFTER-SSIM & 0.6323 & 0.6325 & 0.6132 & 0.6083 & 0.6157 \\
AFTER-RE & 2.2619 & 2.1641 & 2.1818 & 2.0157 & 2.0951 \\
LR & 23.3325 & 19.4949 & 8.2884 & 2.5963 & 0.9145 \\
GRNN & 0.8858 & 0.7012 & 0.7682 & 0.8693 & 0.6035 \\
RF & 0.4155 & 0.4526 & 0.3908 & 0.5342 & 0.7478 \\
Mean & 3.6871 & 3.6871 & 3.6871 & 3.6871 & 3.6871 \\
Single member & 1.2802 & 1.2802 & 1.2802 & 1.2802 & 1.2802 \\
\hline
\end{tabular}

Table 5: The top 34 candidate realisations and their weights.

\begin{tabular}{lllll}
\hline Rank & Model & Number of & Weights & Cumulative weight \\
\hline
\end{tabular}


https://doi.org/10.5194/os-2020-35

Preprint. Discussion started: 13 May 2020

(c) Author(s) 2020. CC BY 4.0 License.

\begin{tabular}{lccll}
\hline & & Members & \\
\hline 1 & MPI-ESM-LR & 9 & 0.4127 & 0.4127 \\
2 & CCSM4 & 15 & 0.2473 & 0.6600 \\
3 & MPI-ESM-MR & 4 & 0.1118 & 0.7718 \\
4 & MIROC-ESM & 3 & 0.0699 & 0.8417 \\
5 & MIROC-ESM-CHEM & 3 & 0.0653 & 0.9070 \\
\hline
\end{tabular}

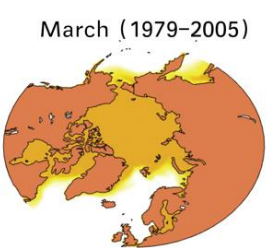

March (2006-2018)
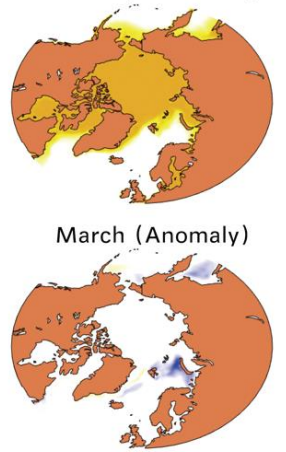

$-100-80-60-40-20$

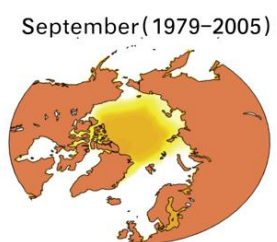

September(2006-2018)

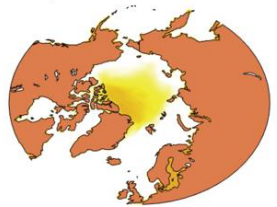

September(Anomaly)

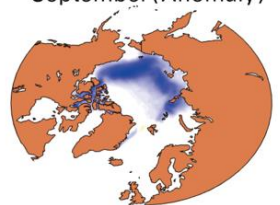

$\begin{array}{lllll}20 & 40 & 60 & 80 & 100\end{array}$

(a)

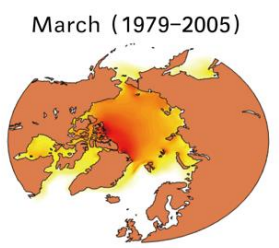

March (2006-2018)
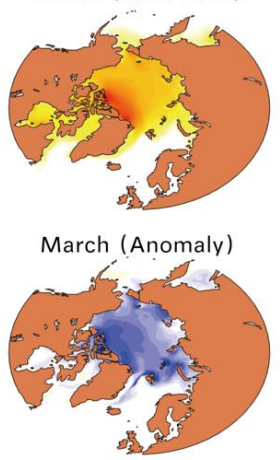

$\begin{array}{lll}-2 & -1 & 0\end{array}$

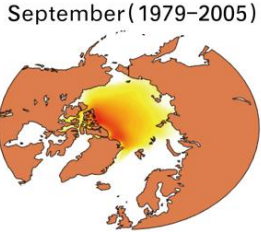

September(2006-2018)

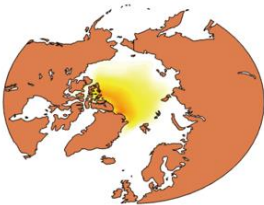

September (Anomaly)

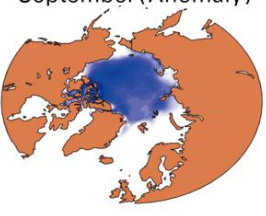

(b)

Figure 1: Variation of SIC (a) and SIT (b) between the current mean state (2006-2018) and historical mean state (1979- 
https://doi.org/10.5194/os-2020-35

Preprint. Discussion started: 13 May 2020

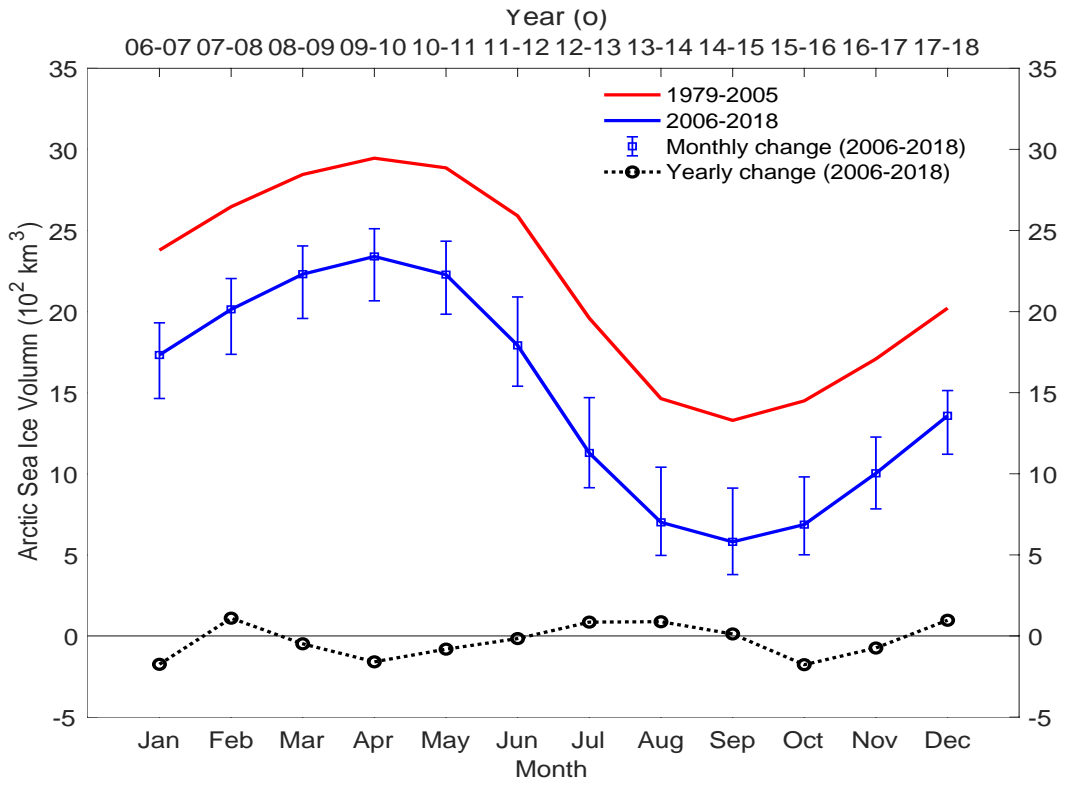

Figure 2: Variation of the SIV; the red line represents the monthly mean SIV from 1979-2005, and the blue line is the monthly mean SIV from 2006-2018. Compared to the mean state from 2006-2018, the monthly SIV change is represented as a light blue error bar and the yearly change is represented by black dots.
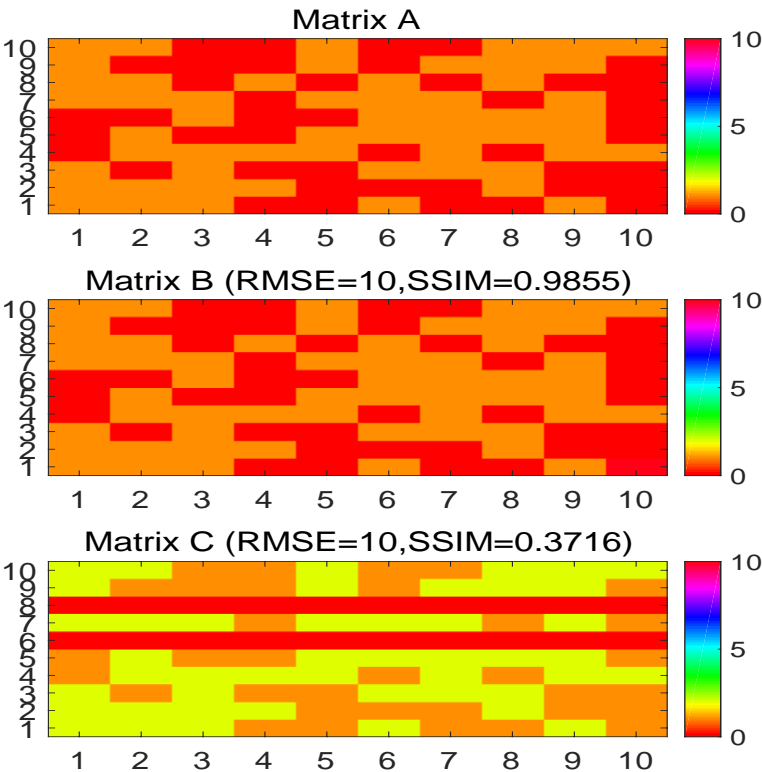

Figure 3: Example for structure similarity analysis. 
https://doi.org/10.5194/os-2020-35

Preprint. Discussion started: 13 May 2020

(c) Author(s) 2020. CC BY 4.0 License.

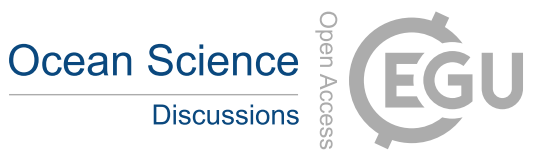

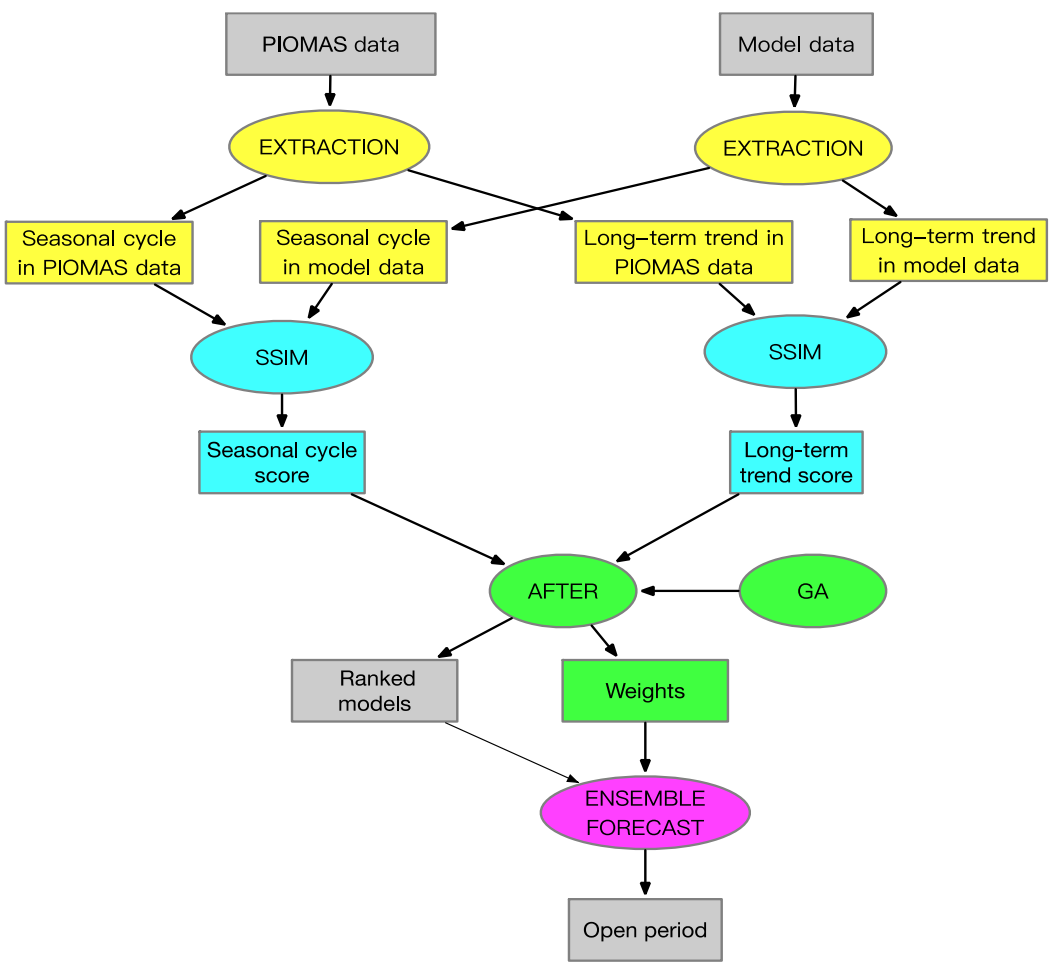

Figure 4: Work flow of the proposed method.

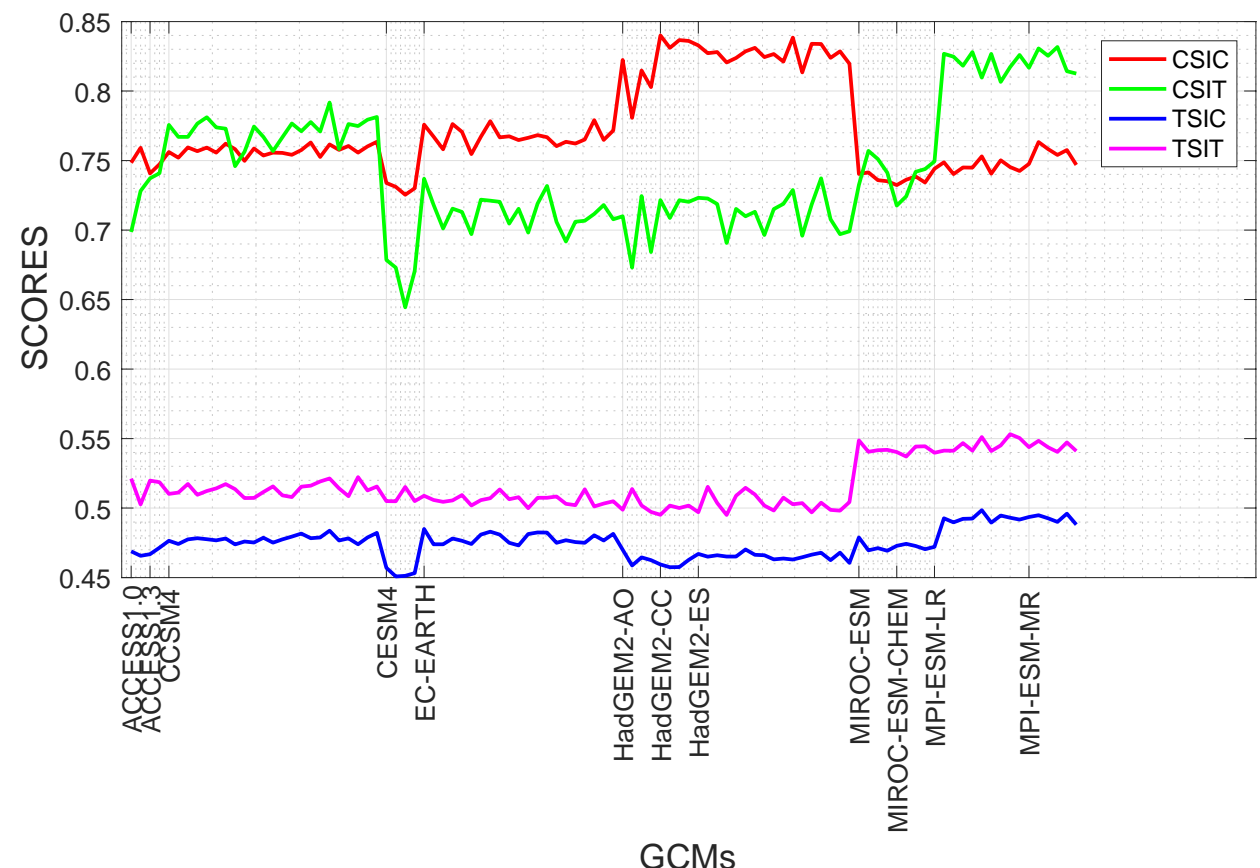


https://doi.org/10.5194/os-2020-35

Preprint. Discussion started: 13 May 2020

(c) Author(s) 2020. CC BY 4.0 License.

Figure 5: Model evaluation and selection with four scores.

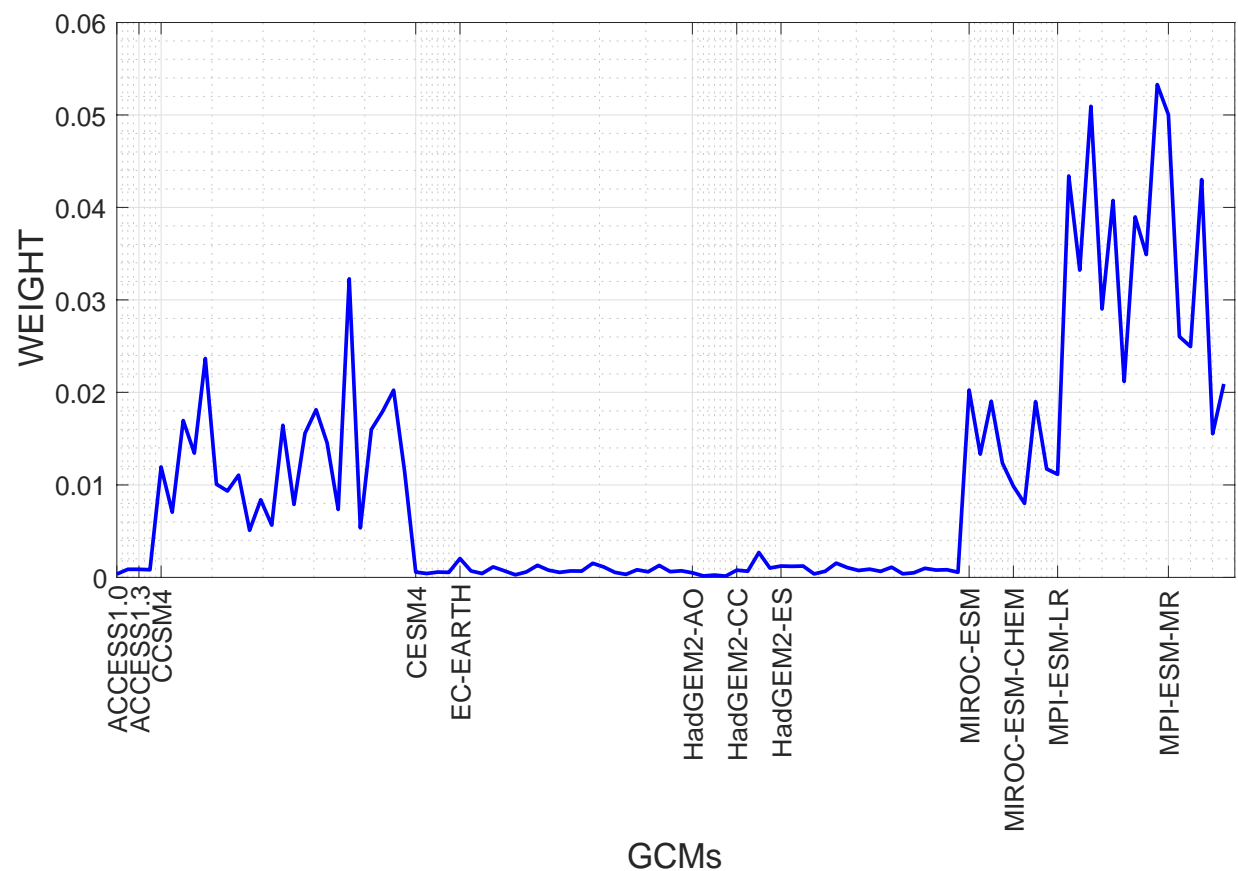

Figure 6: Weight of each candidate model derived by AFTER-SSIM.

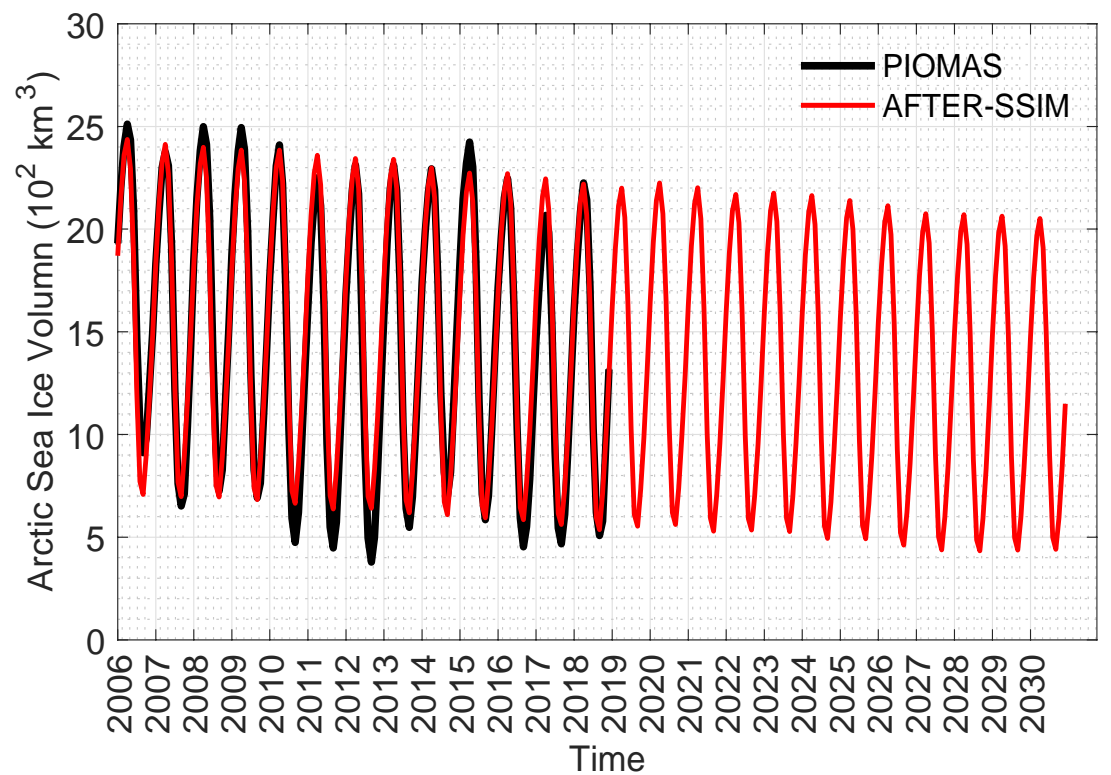



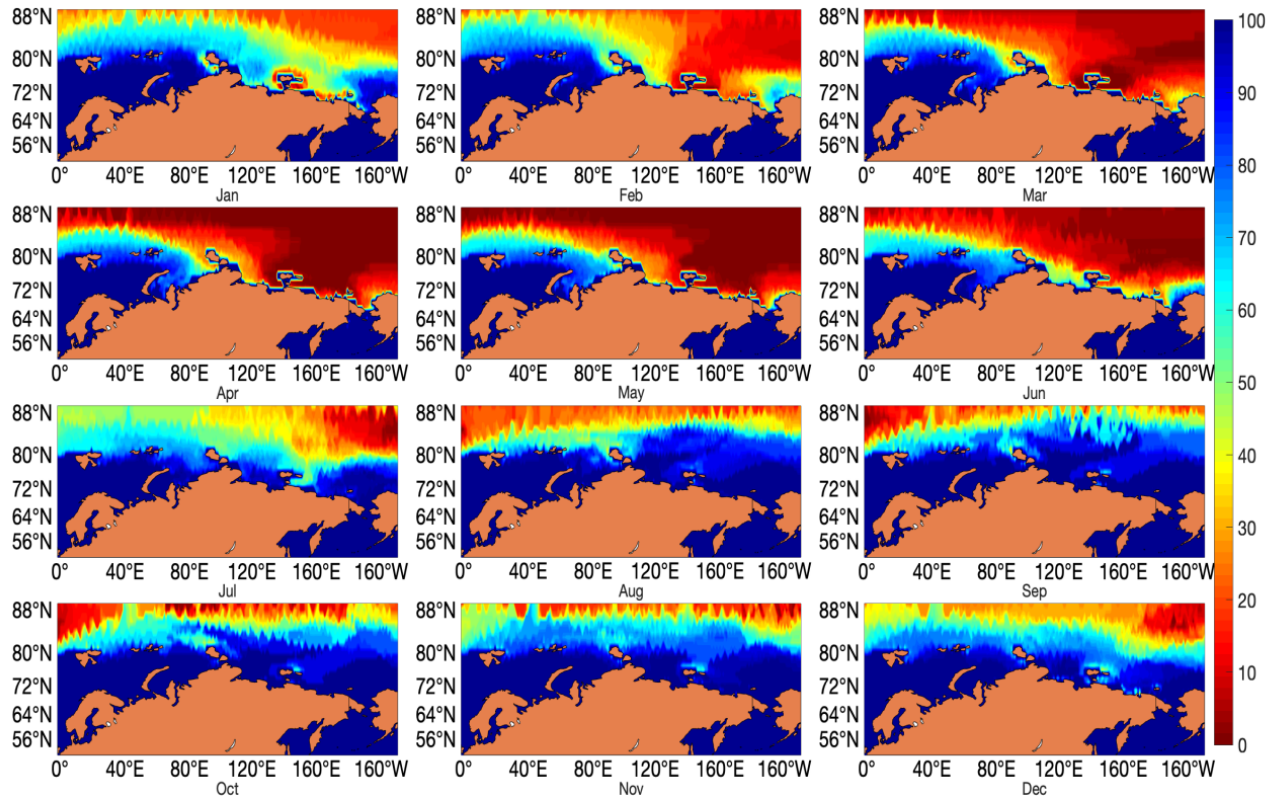

Figure 8. Possibility of navigability for 1A super vessels on the Northern Sea Route for every month in the year of 2030 with 101 combined candidate realisations. 
https://doi.org/10.5194/os-2020-35

Preprint. Discussion started: 13 May 2020

(c) Author(s) 2020. CC BY 4.0 License.

\section{Code and Data availability}

\section{Code:}

Adaptive Forecasting Through Exponential Re-weighting algorithm:

Yang, Y., 2001: Combining forecasting procedures: Some theoretical results. Econom. Theory, 20, 176-222,

https://doi.org/10.1017/S0266466604201086.

Structural Similarity Index Measure algorithm:

Zhou, W., B. Alan Conrad, S. Hamid Rahim, and Simoncelli Eero P, 2004: Image quality assessment: from error visibility to structural similarity. IEEE Trans Image Process, 13, 600-612.

\section{Data:}

ACCESS1.0, ACCESS1.3 datasets:

Bi, D., and Coauthors, 2013: The ACCESS coupled model: description, control climate and evaluation. Aust. Meteorol. Oceanogr. J., https://doi.org/10.22499/2.6301.004.

CCSM4, CESM1 datasets:

Gent, P. R., and G. Danabasoglu, 2011: Response to Increasing Southern Hemisphere Winds in CCSM4. J. Clim.,

24, 4992-4998.

EC-EARTH datasets:

Fichefet, T., and M. A. M. Maqueda, 1999: Modelling the influence of snow accumulation and snow-ice formation on the seasonal cycle of the Antarctic sea-ice cover. Clim. Dyn., 15, 251-268.

HadGEM2-ES, HadGEM2-CC, HadGEM2-AO datasets:

470 Mclaren, A. J., H. T. Banks, C. F. Durman, J. M. Gregory, and S. W. Laxon, 2006: Evaluation of the sea ice simulation in a new coupled atmosphere-ocean climate model (HadGEM1). J. Geophys. Res., 111, C12014.

MIROC-ESM, MIROC-ESM-CHEM datasets:

Watanabe, M., M. Chikira, Y. Imada, and M. Kimoto, 2011: Convective control of ENSO simulated in MIROC.

J. Clim., 24, 543-562.

475 MPI-ESM-LR, MPI-ESM-MR datasets:

Notz, D., F. A. Haumann, H. Haak, J. H. Jungclaus, and J. Marotzke, 2013: Arctic sea-ice evolution as modeled by Max Planck Institute for Meteorology’s Earth system model. J. Adv. Model. Earth Syst., 5, 173-194.

PIOMAS datasets: 
https://doi.org/10.5194/os-2020-35

Preprint. Discussion started: 13 May 2020

(C) Author(s) 2020. CC BY 4.0 License.

Ocean Science

Discussions

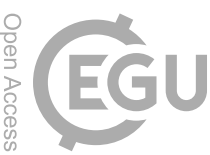

Zhang, J., and D. A. Rothrock, 2003: Modeling Global Sea Ice with a Thickness and Enthalpy Distribution Model

480 in Generalized Curvilinear Coordinates. Mon. Weather Rev., https://doi.org/10.1175/1520-

0493(2003)131<0845:mgsiwa>2.0.co;2. 
https://doi.org/10.5194/os-2020-35

Preprint. Discussion started: 13 May 2020

(C) Author(s) 2020. CC BY 4.0 License.

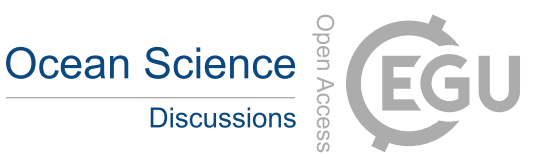

Author contribution

Wang Yangjun: Methodology; Software; Writing- Original draft preparation

485

$\begin{array}{ll}\text { Liu Kefeng: } & \text { Writing - Reviewing and Editing } \\ \text { Qian Longxia: } & \text { Data curation; Validation } \\ \text { Zhang Ren: } & \text { Supervision; Conceptualization }\end{array}$


https://doi.org/10.5194/os-2020-35

Preprint. Discussion started: 13 May 2020

(C) Author(s) 2020. CC BY 4.0 License.

Ocean Science

Discussions

\section{Competing interests}

490 The authors declare that they have no known competing financial interests or personal relationships that could have appeared to influence the work reported in this paper.

The authors declare the following financial interests/personal relationships which may be considered as potential competing interests. 